\title{
What Selection Pressure Does to Mutations Favoring Cancer? Highlights of A Simulation Approach
}

\author{
Kwiatkowski Fabrice ${ }^{1,2 *}$, Serlet Laurent ${ }^{2}$ and Bignon Yves Jean ${ }^{1}$ \\ ${ }^{1}$ Laboratoire d'Oncologie Moléculaire, France \\ ${ }^{2}$ Laboratoire de Mathématique: probabilités et statistiques appliquées, France
}

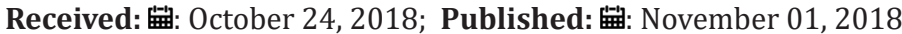

*Corresponding author: Fabrice Kwiatkowski, Centre Jean Perrin, France

\begin{abstract}
Context: research in oncogenetics has focused for years on mutations increasing independently the risk of cancer (ex. BRCA mutations for breast/ovarian cancers). Nowadays, interactions between mutated genes are searched for. Besides, because deleterious mutations shorten life and thus reproduction outcomes, why have they not been eliminated by selection pressure?

Methods: we developed software to test various hypotheses about mutations survival among a theoretical population having main demographic characteristics of a primitive population. Various simulations (Monte-Carlo approach) with various genotypes tested how several deleterious mutated genes with various penetrances could interact and possibly survive despite the life shortening they induce.

Results: simulation over millennia showed that deleterious mutations needed to provide evolutionary compensations such as higher fertility and/or earlier onset of reproductive capacities. This las characteristic was a strong factor enabling deleterious mutations to last. Because in female, menopause terminates the fertility period, iterations tended to select spontaneously mutations favoring cancer after menopause, without any consideration about hormonal exposure. Interactions between highly penetrant mutations were very unlikely to last and tended to split apart populations carrying each different mutation. Some results regarding fertility were validated using our database of 9000 pedigrees at high cancer risk.
\end{abstract}

Keywords: Oncogenetics; Mutation; Cancer; Selection Pressure; Pedigree; Modeling

\section{Introduction}

Very penetrant germline (hereditary) mutations in Human are scarce [1] and reports of de novo mutations are quite rare [2,3]. Even if this statistic is not exactly right, this means that mutations favoring cancer like BRCA1 and BRCA2 are very uncommon events in human's history and it is very likely that present known mutations are quite old (several millennia). Other etiologic hypotheses concerning hereditary cancer risk suggest possible interactions between several weakly penetrant mutations. Whatever the penetrance, these deleterious mutations have a direct impact on life expectancy of carriers (it shortens life time because of diseases that they favor at early ages). One might ask why natural selection, generation after generation, did not eliminate them. This is the issue of this article. To answer this question, the first paragraph describes the methods we used, the population parameter that were necessary, and how they were mixed together to provide an acceptable population-size evolution. The characteristics of the mutations that are introduced in the model are in accordance with the knowledge about BRCA mutations. A stochastic computer routine was developed to simulate what happens along generations to these mutations. First tests concerned the introduction of 5 mutations favoring cancer at different ages that do not provide any specific advantage about fertility. Second tests used various but relevant corrective measures to counterbalance the natural decline of mutations rate among studied population. In a second paragraph, these results are discussed in the light of what is known about BRCA mutations. Observational results are then described: they were obtained from a large database of family presenting with a hereditary cancer risk (more than 9000 families and 190 000 family members recruited since 1985 in Centre Jean Perrin Oncogenetic Department). Limitations and further possibilities are described in the last chapter.

\section{Materials and Methods}

Because the economic changes of these last centuries did not concern all continents at the same time, researchers of more advanced countries could collect data that appear relevant to describe primitive population characteristics. Other works have 
investigated registries to constitute same king of data. From this data, different kind of pyramid of age can be found in the literature:

a) by INED, the French National Institute of Demography [4] for France and England (1750 and 1850)

b) by GLOBOCAN for Saharan Africa in 2002 for example [5].

c) In PROVIDE survey [6] for South-Africa

Most other parameters could be found in publications of the French National Institute of Demographic Studies (INED) or were extracted from a cohort (COSA) of 1962 women that we constituted in our region (middle France) between 1996 and 2006. Half of the women of this cohort were treated for breast or ovarian cancer and the other half constituted a control group seen for prevention consultation. Their age was comprised between 25 and 89 with an average equal to $58 \pm 10$ (standard deviation) [7]. To facilitate the reading of following paragraphs, formulas are grouped in (Appendix 1).

\section{Modeling the Risk of Death}

Although the simulations reported hereafter are performed in a primitive context, three patterns have been modelled: the mortality risk of primitive populations, the one of under-developed countries and the present one typical of industrial countries. The pyramid of age for England in 1851 was chosen to represent a primitive situation: it corresponds to a rather steady risk of death for males and females all along life, with the known high mortality risk during the first 5 years related to the infant mortality excess. The GLOBOCAN pyramid of age for North Africa that appears similar, already shows the impact of medical progress for the first classes of age, with a reduced probability to die during childhood. The former was used to model primitive context while the latter to estimate life expectancy in under-developed countries. Finally for industrialized countries, the 1989 French pyramid of age was used. After these choices, risk of death according to age was calculated, using a polynomial regression. (Figure 1) shows for females how the mortality risk differs depending on context.

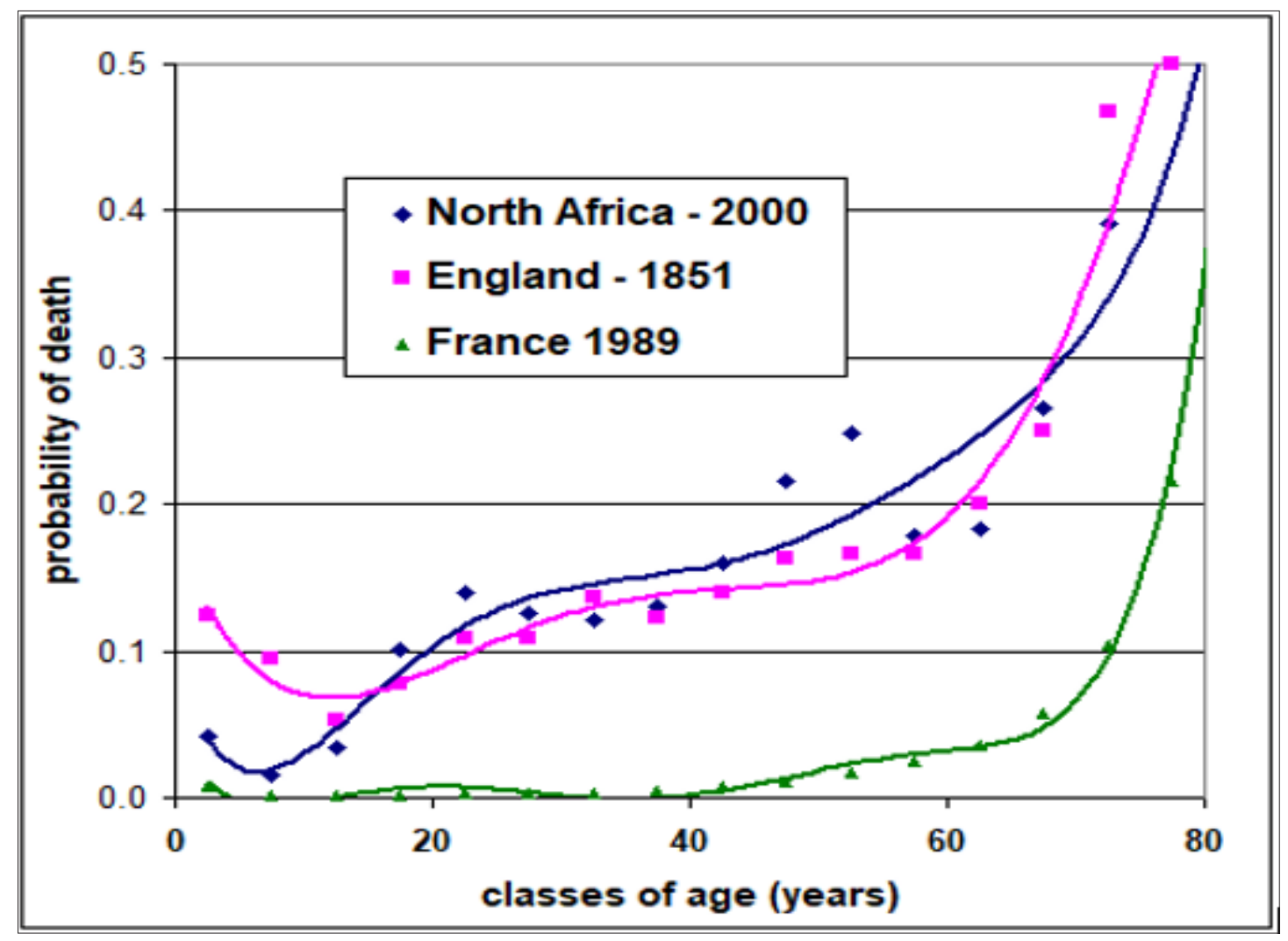

Figure 1: Fitted curves for female mortality by 5-year classes of age and three different contexts.

\section{Marriage}

Marriage (rate and age) has social determinants whatever the civilization. For example, at the end of the $18^{\text {th }}$ century in France, celibacy was enjoined to $12 \%$ of women when they got nun and about $15 \%$ in main cities because of domesticity; earlier, at the end of the $17^{\text {th }}$, childless women were estimated according to church registers between $6 \%$ and $7 \%$ [8]. In our COSA cohort, which represents modern occidental societies, $3.5 \%$ of women never got married or lived in couple less than 3 years and were nulliparous. A $4 \%$ celibacy rate was introduced in our model, but we had no means to check if this value was relevant in a primitive context. Somehow, a celibacy rate seems inevitable because of congenital abnormalities or other possible social rules, even in primitive groups that may forbid marriage to some individuals. The same celibacy rate was attributed to men, although it might sometimes be much higher, for instance if polygamy is permitted: females are 
therefore less available for bachelors and men remain more often alone. Polygamy could be set on in our modelling, but monogamy was the most tested situation. [9] found a mean age at first child of 25 with a standard deviation equal to 5 years.

We decided that this age was also relevant for wedding although one year could have been retrieved (at least 9 months before birth of first child). But in our modelling, it was possible to give birth to a baby just after the wedding, so this correction was not necessary. For primitive populations, we fixed the mean age of first wedding at 18 5 : this agrees with the mean age at first birth that was 18.7 in rural women of Zimbabwe in 1980 [10]. Similar figures were reported by [11] in rural populations of eight countries of Southern and Eastern Africa. The minimum fertility age for females (menarche) was fixed at 13 years, under the null hypothesis. Men were considered fertile at the same age but because average wedding age for males is usually greater than females' one [9], we added 2 years in contrast to women's wedding mean age. Another reason for the older marriage age for men comes from the high maternal mortality rate causing men getting re-married at later ages. The mortality risk at each pregnancy reached 1.5\% during Middle-Age [12] and such figures are still observed in some subSaharan countries conversely to developed countries where a $10 / 100000$ rate is common [13].

\section{Natality Parameters: Number of Children}

Natality corresponds to several parameters, but main statistics evaluate natality rate using fecundity rate per women. INED edited in 2004 a population survey comparing fecundity of French native women to North-African migrant women [14]. Another survey concerned households of South Africa in 1995 [6]. Both sources found a females' fecundity peak at 28-year. Data from Bangladesh contrasted from these previous outcomes [15]: fecundity peak of women between 1960 and 1976 was close to age of 22 years. The 28 years peak was nevertheless chosen although this could be discussed. An earlier fecundity period would shorten intergeneration intervals and would accelerate the modeled process. Our choice is thus more conservative (it does not interfere with events that we search for: it only delays them). We also considered that fecundity in women was a stable variable and neither social nor medical factors could let final fecundity rates vary. These parameters were used to compute the fecundity curve for primitive population. Another parameter, that does not seem to depend on social factors, is the miscarriage rate. This rate reduces significantly the final number of viable children. In our COSA cohort, this rate almost reached $20 \%$ of all pregnancies. Other population surveys have reported similar statistics [16-18]. Owing to the antiapoptotic properties of BRCA genes, we made this rate variable to evaluate possible compensations for the deleterious role of tested mutations. The maximum absolute reduction of this rate was set to $10 \%$ although in a population-based analysis, this diminution reached one third [19].

\section{Gender of Children and Mutation Transmission}

Normally, to compensate for the higher male infant mortality, more males get born than female. In France, 105 males get born for 100 females, thus a probability to be a male of $51.2 \%$. This percent was kept in our modeling. The chance for a child to receive a mutated gene from one of his parents is $50 \%$. In our modeling, this value was set for each possible mutation.

\section{Age of Menopause}

In our COSA cohort, mean age of menopause was $51 \pm 3.8$ years and its distribution was Gaussian. This age is rather stable worldwide: for example the same age was reported in a large Norway cohort [20] and a slightly younger age $49.3 \pm 3.4$ in a large Japanese cohort [21]. This parameter is very important because reproduction period length (time from menarche to menopause) has a direct impact on natality outputs. In our model, we fixed the mean menopause age at $50 \pm 5$ years. Of course, because of usual early mortality in primitive population, most of simulated women died before menopause. Of course, because of usual early mortality in primitive population, most of simulated women died before menopause.

A limitation of male fertility must be questioned. A Canadian study based on ancient family registries [22] showed that male widows continued to get married and to have children even when they were 60 years old or more. In this survey, chosen old men were married with women younger than 30 . They contributed to an average of 2.2 children which was compared to 2.8 children for men married before they were 30 . This small decline with age can be justified by studies of semen quality among men of various ages [23], that show a slight but constant yearly reduction after 30 years of sperm motility and concentration. However, this decrease happens to be inferior to the one due to environmental changes (nutrition, life habits, pollution...): for instance between 1973 and 1992 the decrease of motile and normal spermatozoa in fertile French men was higher among young adults of each period than the decrease caused by age. Other reproductive problems may occur also for older men such as congenital anomalies whose rate increases with age [24]. Considering also that a reduced correction of male fertility rate would be of insignificant value as it would apply to a very limited population (most of men die before 50 in a primitive context) in our modeling, no upper limit was fixed to male fertility age.

\section{Cancer Risk and Incidence}

Incidence and mortality of cancer statistics were available in FRANCIM report [25]. For women older than 20, the risk to develop a breast cancer according to age exhibited a peak between the ages of 60 and 64 . In the COSA study, the peak was $58 \pm 12$ years and distribution was almost gaussian. The cancer incidence curve to simulate cancer risk was set gaussian with a 5-year standard deviation, considering cancers caused by mutation happen much earlier and in a more grouped fashion. Breast cancer is supposed to induce death in the following 5 years in $30 \%$ of cases. This cancer stops rapidly fecundity. In our modeling, the end of fecundity (for both gender) was set at disease onset and we made the average delay till death equaled to $5 \pm 5$ years although this is a very optimistic hypothesis. All cancers prognosis was supposed to follow the same gaussian shape. Penetrance is the cumulative 
rate of disease occurring in a population of mutation carriers. For BRCA mutations, penetrance is supposed to vary according to environmental conditions: for example BRCA penetrance is close to $70 \%$ today which means that $70 \%$ of mutated women will have a breast or ovarian cancer during their life-time.

Some life habits can change this penetrance (breast feeding, parity, nutrition, physical activity) and the BRCA penetrance was supposed to be much lower, around $50 \%$ one century ago. In our modeling, this parameter could be changed, but calculations reported hereafter were performed using a $50 \%$ penetrance. Sporadic cancers have also been considered, to better fit reality: indeed, main difficulty in population survey is often to distinguish between sporadic cancers and those favored by hereditary factors. An interesting work of [26] showed that most of cancers happen randomly at a frequency that increases proportionally with the number of cell divisions in tissues during life (correlation $r=0.81$ ), therefore with age too. To implement the risk for sporadic cancer, we used epidemiological data reported by the department of UK cancer research 2012-2014 [27]. In case of competing cancer risk, that is a familial one associated to a sporadic one, the first occurring - most of the time the familial cancer - was kept. There is no biological reason to believe that this proportionality was different in the ancient times.

\section{Mutations Geographic Spread Map}

Simulations have also investigated how deleterious mutations dissemination could be influenced by geographical aspects. A virtual map was created, and individuals were randomly spread on it at the beginning. Travels across the map were limited by generation and distances were limiting factors for individuals to find a spouse. Different conditions were tested as for example mutations interacting in synergy or not regarding the cancer risk.

\section{Complementary Parameters}

We supposed that marriage lasted until death (no divorce), that marriage was not possible between brothers and sisters, parents and children, while more distant filiations were admitted forming new couples. After the death of a spouse, the widow could get married again, except menopausal women in order not to reduce men's descendance (as a man getting married with a menopaused woman would not expect a child). Polyandry was not implemented as it seems to be a very rare social rule in Man's history.

\section{Randomization for the Monte-Carlo Simulations}

Two algorithms were implemented:

a) the standard random function of Microsoft Visual Basic (a random table) with a pointer re-initialized by the timer function at the beginning of main loops.

b) Mersenne-Twister algorithm [28]: it is a validated algorithm that generates pseudo-random numbers.

Tests performed using both algorithms yield similar statistics, but the second algorithm was 10 times slower than the first one. For the calculations reported hereafter, the first algorithm was thus used.

\section{Interface to Enter Parameters}

A user-friendly interface enables to introduce calculation parameters. It includes:

a) Iterations number (default $=100$ )

b) Size of the initial population $(2000=1000$ females and 1000 males)

c) Length of the period during which the test is to be carried on (2000 years)

d) Time slice for the statistics (100 years), i.e. 20 checkpoints if period lasts to 2 millennia as above.

e) Type of mortality curve, i.e. age pyramid. We used here the primitive context.

f) Average fecundity per women (ex. 2.1 for a developed context)

g) Polygamy permitted or not (no)

h) Number of mutations to test (5)

i) Initial frequency of mutation carriers per mutated gene (5\%)

j) Impact of these mutations on fecundity:

a. Miscarriage risk set to $20 \%$ (and decrease to 5\%)

b. Marriage precocity ( \pm 2 years, default $=0$ )

c. Synergy between mutations: yes/no and number of mutations necessary for this synergy to work

k) Mutations penetrance (50\%)

l) Synergy between mutations: yes/no and number of mutations necessary to make penetrance cumulative.

m) Gender concerned by the cancer risk (males, females or both)

n) Age peak for penetrance: the age when most cancers related to the mutation occur (ex. 40 years)

o) Progressive penetrance precocity (years): if 5 mutations are studied with a median peak for cancer susceptibility $=40$ years, a 10-year precocity, would attribute to the first mutation a cancer risk peak at $(40-2 \times 10)=20$ years, and 30, 40, 50, 60 respectively to the four other mutations.

\section{Verification}

An EXCEL routine was developed to check how families were generated by our software: this routine enables to draw for each family the resulting pedigrees (Figure 2). The legend of the figure describes main symbols signification. Mutations are indicated using a lowercase letter added to the subject number when needed. Statistics consist in means and standard deviations calculated for each parameter over the total number of iterations. They are registered at each time slice, as for example every century if check points are scheduled by intervals of 100 years (Appendix 2). 


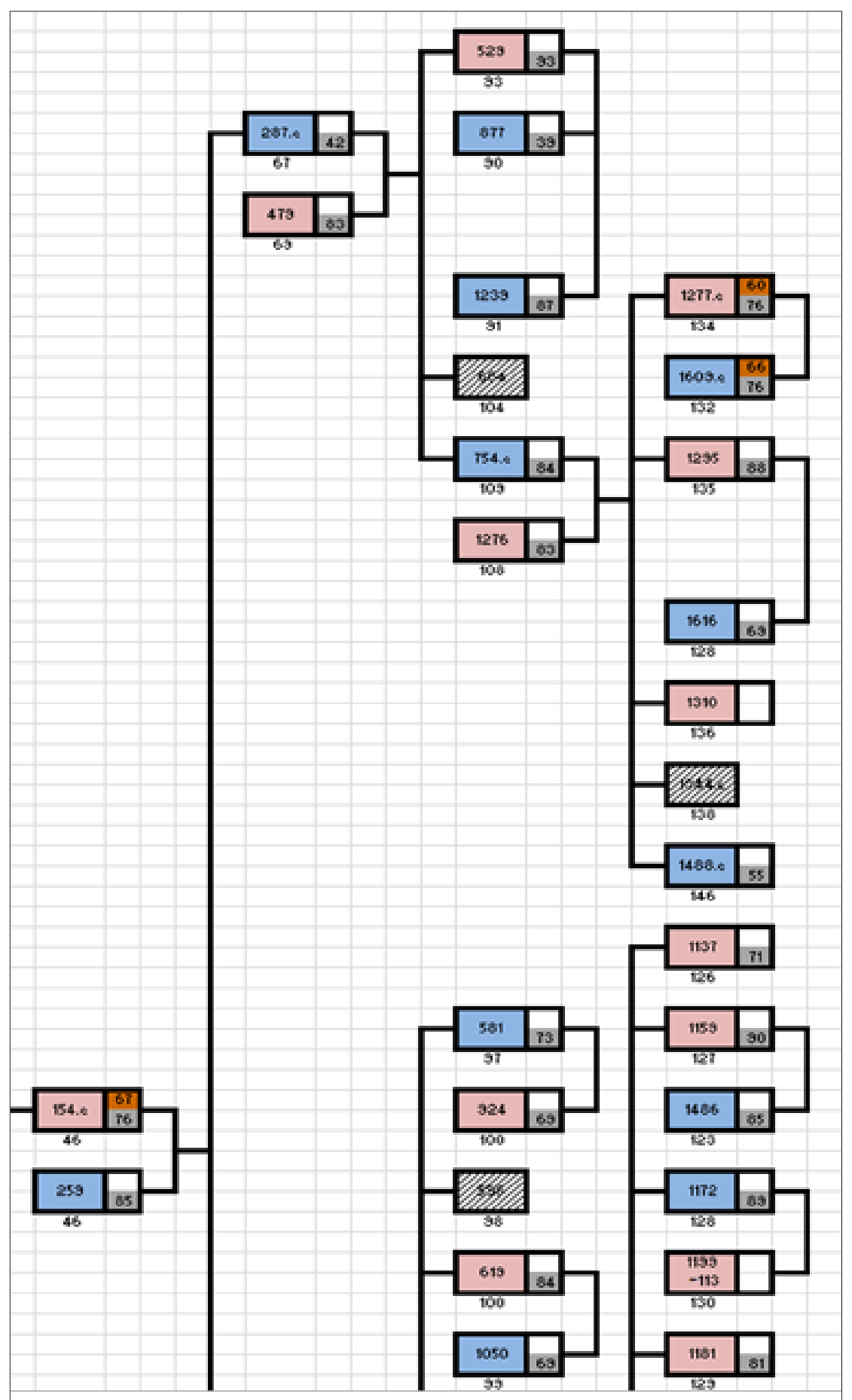

Figure 2: Partial view (4 generations) of a pedigree generated by our software and drawn using a VBA-EXCEL routine to verify the shape of resulting families: female $=$ pink rectangle, male $=$ blue rectangle, orange $=$ familial cancer + age at occurrence, yellow $=$ sporadic cancer (none here), grey age at death and hatched $=$ miscarriage.

\section{Results}

Results presented hereafter were obtained using simulations within a primitive context, considering this was the case most of the time homo-sapiens existed (>50 millennia). Also, only two millennia of evolution were evaluated by calculation, enough duration to notice already significant evolutions.

\section{Tests with No Deleterious Mutation}

Under the null hypothesis, i.e. no deleterious mutations introduced into the model, final pyramid of age (Figure 3) kept the shape corresponding to the type of context selected by the user (developed, under-developed or primitive). 

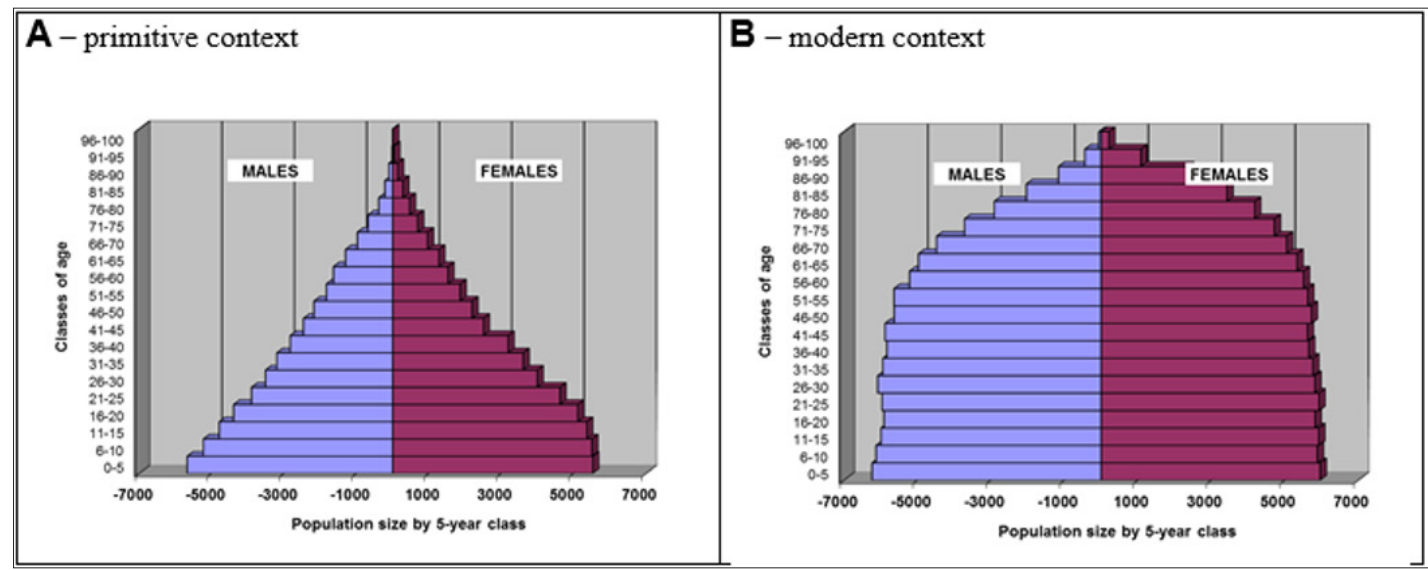

Figure 3: Pyramid of age of the last century after 2 millennia of follow-up resulting from simulations according to two contexts: primitive and modern.

\section{Tests with Five Deleterious Mutations but without Impact on Fertility}

Five deleterious mutations were added to the model. Each mutation was supposed to favor cancer at different ages and concerned both men and women. Mutations were then randomly assigned to $5 \%$ of the initial population (the 20-year old couples). So, about $25 \%$ of the population carried at least one mutation. After all iterations were performed by the program, a longitudinal diagram was drawn (Figure 4A). Mutations that favor a cancer before 30 years were rapidly eliminated, while the two mutations inducing cancer around or after menopause tended to "survive". Other statistics were calculated: figure 4B represents the evolution of underlying population characteristics, still in a primitive context. Except for cancer age, ages at each event were stable: ages of women at their children births. Mean age of deaths, if we exclude the artifact of first century, exhibited no evolution and stayed close to 35 years as well as mean menopause age around 50, that is for women that did not die before. This is true also for cancers: average age at cancer onset is higher than average age of death because cancer concerned only individuals that reached the age of each cancer risk.
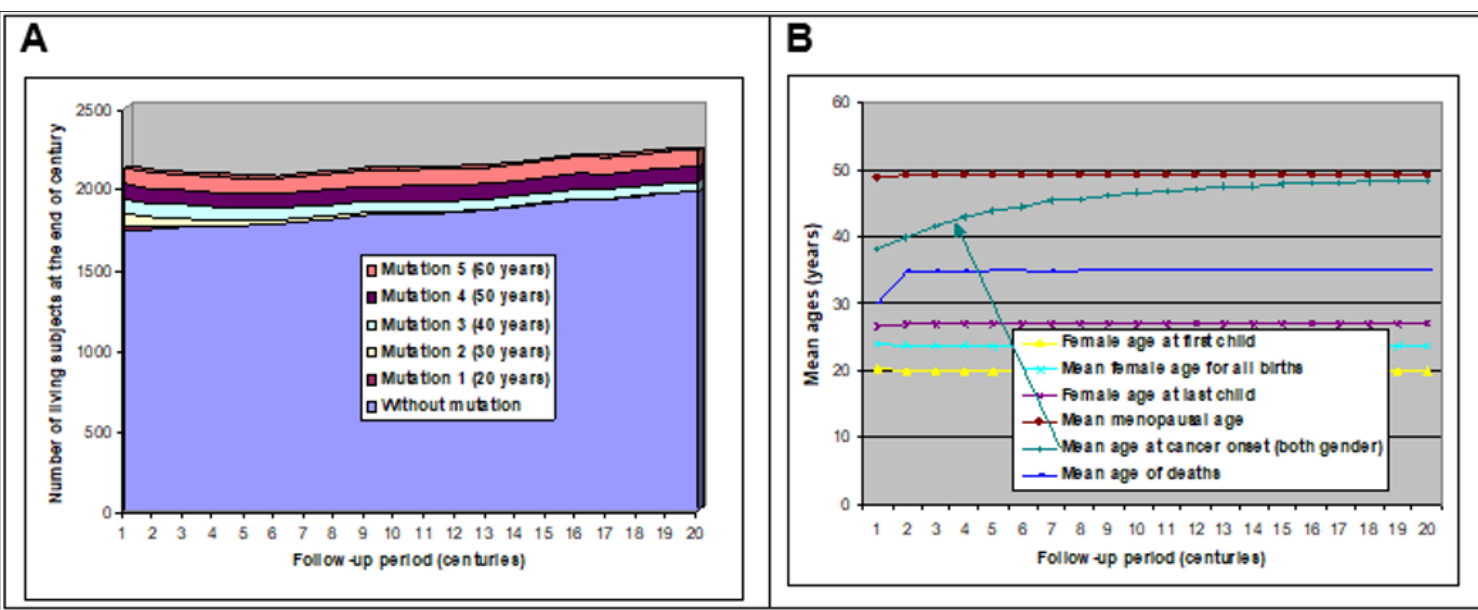

Figure 4: Population evolution according to 5 types of mutation inducing a $50 \%$ cancer risk occurring in average at 5 ages [20$60]$ in men and women (follow-up: 2 millennia).

A-Evolution of population size.

B-Evolution of ages for different events.

The most interesting trend concerned the mean age of cancer onset (marked by an arrow in (Figure 4B)). Year after year, this mean age increased until it almost reached menopause mean age. This highlights how selection pressure works: because carriers of mutations favoring the most precocious cancers die rapidly, their reproduction period is shortened, and their offspring is reduced. Thus, generation after generation, these carriers become less, and less numerous and worst mutations disappear. Precocious cancers then become rarer and mean age at cancer onset increases. This phenomenon tends to reduce the incidence of all major diseases happening before menopause. Hence, without any hypothesis about the etiology of cancers, it evidences that onset of cancers is likely to happen naturally near menopause or after. This selection happens also for men if partners' ages are often similar: but this relationship is indirect. 


\section{Tests with Five Deleterious Mutations Providing a Fertility Advantage}

As concluded above, ancient mutations favoring early cancer in human should have disappeared with time. But it is not the case. Thus these mutations must have provided some evolutionary advantages. Two possibilities were tested in our simulations: they permitted to compensate for the loss of reproductive chances. The first one was a reduced miscarriage rate, and the second an earlier onset of reproduction period (i.e. by reducing first marriage age). As in (Figure 4), the two most deleterious mutations were eliminated during the first millennium, although penetrance was set at $50 \%$ (half of mutation carriers would have a cancer if they did not die before from another cause). First difference concerned the overall size of the population which grew steadily, especially when mutated women could get pregnant one year earlier: the global increase was $11.3 \%$ for (Figure 5A) and $20.4 \%$ for (Figure $5 B$ ) versus $5.6 \%$ in figure 4 when no compensation was introduced. Interestingly, non-mutated individuals seemed to benefit as others from the reproductive advantage of slow penetrant mutations. Final proportion of mutation carriers were respectively $15.5 \%$ when the advantage was a $5 \%$ miscarriage risk reduction and $17.3 \%$ if reproduction begun one year earlier. As 3 of the 5 mutations remained at the end of the follow-up period, it suggests the proportion of mutation carriers should increase in the following millennia, especially for the latter advantage.

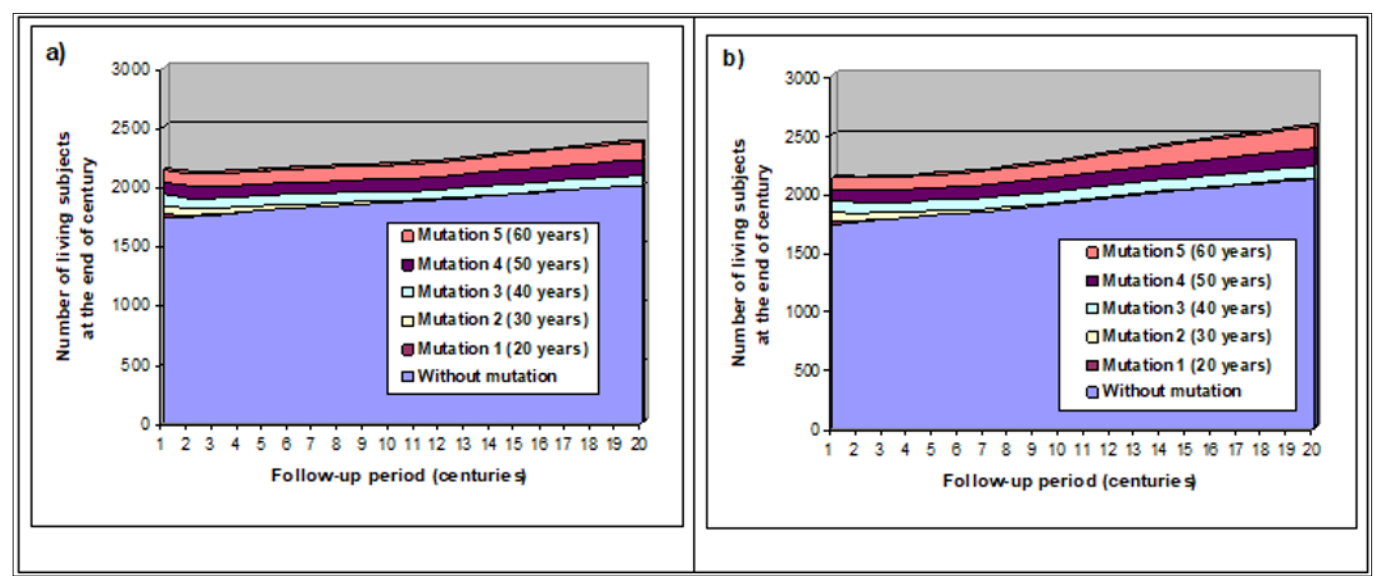

Figure 5: Impact of two types of reproduction advantages.

Note:

a) with a $5 \%$ absolute decrease of miscarriage risk (15\% instead of $20 \%$ ).

b) with a 1-year advance of reproduction onset.

\section{Tests With 5 Mutated Genes that May have a Synergy Together}

Results did not differ much from previous situations. The best condition for the mutations to spread was when: a) They gave reproductive advantages but did not favor cancer when they were alone.

b) Cancer risk was heightened only when two or more mutations were carried by individuals.

\section{Geographic Dissemination of Synergic Deleterious Mutations}

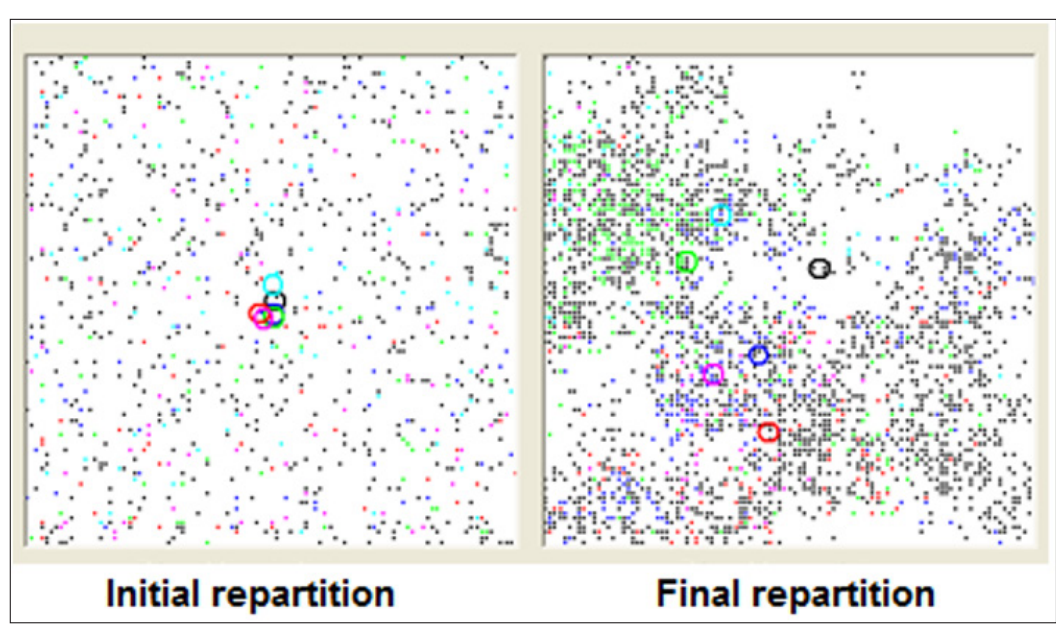

Figure 6: Spontaneous geographic dissemination of 5 mutations increasing cancer risk when individuals carry more than one of them: black points and circle correspond to individual carrying no deleterious mutation. Other circles locate the centroid of mutation carriers. 
When deleterious mutations do not interact, location of carriers covers the map at random. Centroids of mutation carriers remain close to the center of the map. Frequently though, the map gradually exhibits empty zones that individuals leave because of the absence of enough potential partners. Polygamy only seemed to slow down a little this evolution. When mutations have a synergic influence on cancer occurrence, populations of carriers spread significantly across the map and centroids deviate from each other (Figure 6).

\section{Discussion}

Because genetic research concerning species evolution is long difficult and expensive, it is tempting today to perform simulations to limit ground investigations. The same approach exists in other scientific fields such as astronomy and climate, and they have already brought much essential knowledge. The simulations described here in the field of oncogenetics, required a much simpler software and could be performed on a desktop computer. Calculations testing each situation lasted a few hours (at most a few days), enough to obtain stable statistics using one hundred iterations per tested condition. Larger numbers of iterations (500 and 1000) were tested without gain in accuracy and/or differences between resulting evolutions. An initial population size of 2000 persons (1000 males and 1000 females) seemed to be the minimum necessary to yield a good stability of outcomes. Although initial population contained only members of identical age (20 years), the ending pyramid of age (built using data of last century) was correctly matched with the theoretical one, whatever the context used (developed, under-developed or primitive). Finally, the type of generator of pseudo-random numbers did not alter the global performance of the modeling. The most difficult part of the modeling was to find reliable data (age pyramids) likely to fit with life conditions of our ancestors. Because modern way of life did not concern all populations on earth during the past century, it was possible to obtain good estimators of age-related survival probabilities of primitive populations. We considered other biologic parameters (fecundity, menopause...) stable since long, and assumed that they were same as now. Some hypothesis was made concerning ancient marriage habits, and when this was not relevant (for example polygamy), we chose to add parameters that could enable to test various situations.

Overall, population evolutions were compared with or without mutation carriers but under the same context conditions (fertility...). We could question if altered conditions would not yield major changes in our conclusions. Many other tests have been realized: main changes only modified the period length necessary to evidence the differences that we reported. Insignificant results were not described above in particular the impact of polygamy, despite age matching between spouses was deactivated. This could be expected because the several wives of each polygamous man were no more available for other bachelors. The fact that cancers would concern a gender rather the other one, was neither of major importance. But this could come from the preference that was computed: partners of similar ages were first sought for marriages, and because this was usually possible, spouses tended to be well age-matched. Therefore, cancers impacting exclusively males or females, although new marriages were possible, had a global identical effect on reproduction outputs.

Reproductive advantages can result from various biological parameters and because of behavioral changes: only a fertility increase was tested (by reducing the rate of miscarriages), and no other possibility was implemented since they all would end up with a similar percent increase. An earlier onset of the reproduction period was also envisaged because this has a different impact on offspring: the number of children increases mainly because parents that begin earlier reproduction escape from causes of death they are supposed to meet later. In our modeling, because menopause age was not reduced by the same advance duration, the enlargement of reproduction period could also play a role, although minor as life expectancy usually limits this advantage. Our modeling is nevertheless compatible with Bjelland's findings that evidence only a modest reduction of menopause age when menarche occurs earlier [20].

The geographic simulations brought interesting conclusions: when mutations have a synergic impact on cancer risk, they tend to diverge from each other. This reflects the disappearance along time of individuals carrying several mutations and/or polymorphisms that alone would have no effect on cancer occurrence. This is of major importance: it is possible that today, an increased incidence of cancer may be caused by the population melting. Indeed, because it is so easy to travel over long distances, inhabitants of different countries/even regions - carrying "safe" polymorphisms resulting from an environment-related selection pressure lasting for centuries - meet "again" together and exchange through their descends mutations that were and still are deleterious together. Some population study should investigate this issue to confirm or infirm this hypothesis.

Main weakness of our modeling concerned the uniformity of the context. When a "primitive" context was set at the beginning of simulations, it was alike at the end of simulations, that is after two (or more) millennia. This cannot adequately fit the two last millennia of mankind. Evidently, this suggests that mutations that could provide an evolutionary advantage in the past, may on the contrary become nocuous today as considerable changes have altered man's environment (birth control). Another weakness may come from the complexity of the genetic biology: we tested synergies between only 5 mutations without real improvement of reported results. But the relationships between the \pm 30000 genes of our genome may be able to produce completely different adaptation features. The debate thus remains opened, especially for low penetrance mutations that can mix by hundred their interactions. Conclusions resulting from our simulations have been tested among a very large database of pedigrees $( \pm 9000$ families including more than 190000 members). They have shown that mutated families had indeed more children and less miscarriages. They also use to have they first child earlier than non-mutated families. Surprisingly, this was also true when mutated members were males instead of females [19,29]. 


\section{References}

1. Thomtson, Thomtson (2004) Genetics in medicine. In: Robert Nussbaum (Eds.). ( $6^{\text {th }}$ Edn), Saunders, Philadephia, p. 84-85.

2. Van der Luijt RB, Van Zon PH, Jansen RP, van der Sijs Bos CJ, Wárlám Rodenhuis CC, et al. (2001) De novo recurrent germline mutation of the BRCA2 gene in a patient with early onset breast cancer. J Med Genet 38(2): 102-105.

3. Diez O, Gutiérrez Enríquez S, Mediano C, Masas M, Saura C, et al. (2010) A novel de novo BRCA2 mutation of paternal origin identified in a Spanish woman with early onset bilateral breast cancer. Breast Cancer Res Treat 121(1): 221-225.

4. Vallin J, Caselli G (1999) Quand l'Angleterre rattrapait la France. INEDPopulation et sociétés 346: 1-4.

5. IARC Descriptive Epidemiology Group (2002) GLOBOCAN -cancer incidence, mortality and prevalence worldwide.

6. Punt C, Pauwn K, Mohube E, Gilimani B, Rantho L, et al. (2003) Demographics of South African Households - 1995. PROVIDE background paper 3: 1-22.

7. Delort L, Kwiatkowski F, Chalabi N, Satih S, Bignon YJ, et al. (2007) Risk factors for early age at breast cancer onset - The "COSA program" population-based study. Anticancer Res 27(2): 1087-1094.

8. Henry L, Houdaille J (1978) Célibat et âge au mariage aux XVIIIe et XIXe siècles en France I. Célibat définitif. In: Population, $33^{\mathrm{e}}$ année, ${ }^{\circ} 1$ : $43-$ 84.

9. Levy ML, Sardon JP (1982) L'écart d'âge entre époux. INED-Population et sociétés 162: 1-2.

10. Thomas D, Maluccio J (1995) Contraceptive choice, fertility, and public policy in Zimbabwe. Living Standards Measurement Study (LSMS) working paper 10(1): 1-60.

11. Harwood Lejeune A (2000) Rizing age at marriage and Fertility in Southern and Eastern Africa. European Journal of Population 17: 261280.

12. Matart BY (1994) Approche de la mortalité maternelle au Moyen-Age en Provence. Actes des 6e Journées Anthropologiques. Dossier de documentation archéologique $\mathrm{n}^{\circ} 17$. CNRS Editions, Paris, France.

13. World Health Organization (2014) Trends in maternal mortality: 1990 to 2013. Estimates by WHO, UNICEF, UNFPA, The World Bank and the United Nations Population Division. ISBN 9789241507226.

14. Toulemon L (2004) La fécondité des immigrés: nouvelles données, nouvelle approche. INED-Population et sociétés 400: 1-4.

15. Amin R, Farukee R (1980) Fertility and its regulation in Bangladesh. Bank Staff Working Paper $n^{\circ} 383$. The World Bank, Washington, USA.

\section{ISSN: 2574-1241}

DOI: $10.26717 / B J S T R .2018 .10 .001989$

Kwiatkowski Fabrice. Biomed J Sci \& Tech Res

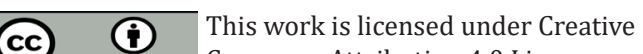

This work is licensed under Creative

Commons Attribution 4.0 License

Submission Link: https://biomedres.us/submit-manuscript.php
16. Zinman MJ, Clegg DE, Brown CC, O Connor J, Selvan SG (1996) Estimates of human fertility and pregnancy loss. Fertil Steril 65(3): 503-509.

17. Buss L, Tolstrup J, Munk C, Bergholt T, Ottesen B, et al. (2006) Spontaneous abortion: a prospective cohort study of younger women from the general population in Denmark. Validation, occurrence and risk determinants. Acta Obstet Gynecol Scand 85(4): 467-475.

18. Katz VL (2007) Spontaneous and recurrent abortion: etiology, diagnosis, treatment. In: Katz VL, Lentz GM, Lobo RA, Gershenson DM (Eds.) Comprehensive Gynecology (5th Edn) Philadelphia, PA: Mosby Elsevier

19. Kwiatkowski F, Arbre M, Bidet Y, Laquet C, Uhrhammer N, et al. (2015) BRCA Mutations Increase Fertility in Families at Hereditary Breast/ Ovarian Cancer Risk. PLoS One 10(6): e0127363.

20. Bjelland EK, Hofvind S, Byberg L, Eskild A (2018) The relation of age at menarche with age at natural menopause: a population study of 336788 women in Norway. Hum Reprod 33(6): 1149-1157.

21. Otsuki S, Saito E, Sawada N, Abe SK, Hidaka A, et al. (2018) Female reproductive factors and risk of all-cause and cause-specific mortality among women: The Japan Public Health Center-based Prospective Study (JPHC study). Ann Epidemiol 28(9): 597-604.

22. Payeur F (2008) Les registres démographiques renseignent sur la fertilité de l'homme en fonction de l'âge. Bulletin 335 de l'ambassage de France au Canada.

23. Auger J, Kunstmann JM, Czyglik F, Jouannet P (1995) Decline in semen quality among fertile men in Paris during the past 20 years. NEJM 332(5): 281-285.

24. Wagner L (2004) Fertilité de l'homme vieillissant. Prog Urol 14(4): 577582.

25. Menegoz F, Cherie Challine L (1999) Le cancer en France: incidence et mortalité. Situation en 1995-evolution entre 1975 et 1995. Editions INSERM, Paris, France.

26. Tomasetti C, Vogelstein B (2015) Variation in cancer risk among tissues can be explained by the number of stem cell divisions. Science 347(6217): 78-81.

27. Cancer Research UK (2016) URL. Access: September 2018.

28. Matsumoto M, Nishimura $T$ (1998) Mersenne-Twister, a 623-dimensionally equidistributed uniform pseudo-random number generator. ACM Transaction on Modeling and Computer Simulation 8(1): 3-30.

29. Guay JH (2013) Perspective Monde-outil pédagogique des grandes tendances mondiales depuis 1945. Sherbrooke University, Canada.

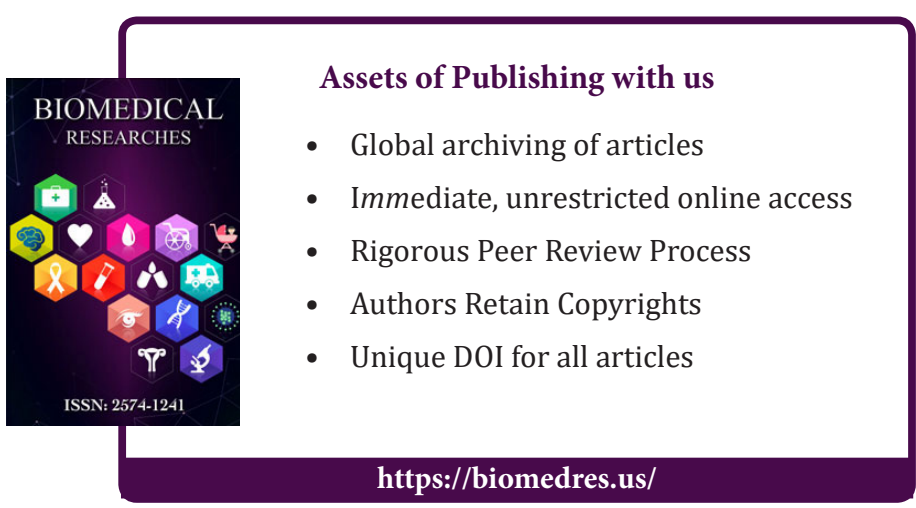

